\title{
A Comparison of Lexeme and Speech Syllables in Dutch*
}

\author{
Niels O. Schiller, Antje S. Meyer, R. Harald Baayen, and Willem J. M. Levelt \\ Max Planck Institute for Psycholinguistics, Nijmegen, The Netherlands
}

\begin{abstract}
The CELEX lexical database includes a list of Dutch syllables and their frequencies, based on syllabification of isolated word forms. In connected speech, however, sentence-level phonological rules can modify the syllables and their token frequencies. In order to estimate the changes syltables may undergo in connected speech, an empirical investigation was carried out. A targe Dutch text corpus (TROUW) was Iranscribed, processed by word level rules, and syllabified. The resulting lexeme syllables were evaluated by comparing them to the CELEX lexical database for Dutch. Then additional phonological sentence-level rules were applied to the TROUW corpus, and the frequencies of the resulting connected speech syllables were compared with those of the lexeme syllables from TROUW. The overall correlation between lexeme and speech syllables was very high. However, speech syllables generalty had more complex CV structures than lexeme syllables. Implications of the results for research involving syllables are discussed. With respect to the notion of a mental syllabary (a store for precompiled articulatory programs for syllables, see Levelt \& Wheeldon, 1994) this study revealed an interesting statistical result. The calculation of the cumulative syllable frequencies showed that $85 \%$ of the syllable tokens in Dutch can be covered by the 500 most frequent syllable types, which makes the idea of a syllabary very attractive.
\end{abstract}

\section{INTRODUCTION}

Syllables play an important role in speech production and perception, as well as in language acquisition. Syllables are the first linguistic units that appear in the course of language acquisition (Liberman, Shankweiler, Fischer, \& Carter, 1974). They are earlier accessible than phonemes (Ferguson, 1976; Jusczyk, 1994; Jusczyk, Jusczyk, Kennedy, Schomberg, \& Koenig, 1995 ) and help the child learn prosodic features of the language such as rhythm, i.e., the alternating pattern of strong and weak syllables (Gerken, 1994; Wijnen, Krinkhaar, \& Os, 1994; Schwartz \& Goffman, 1995). Some researchers (e.g., Berg, 1992; Mehler, Segui, \& Frauenfelder, 1981 a) have suggested that children first have a phonological representation that is essentially syllabic, and only later acquire a phonemic rep. resentation.
In a study by Bertoncini and Mehler (1981) it turned out that 4-week-old infants do much better in discriminating syllable-like stimuli than non-syllable-like stimuli. The authors concluded that infants were able to distinguish between syllables that were allowed in the language under consideration whereas this was not the case with phonologically impossible syltables, although the phonetic manipulations were the same. In fact, there is much evidence available for the syllable being the basic processing unit during speech acquisition.

There are, however, differences with respect to the $\mathrm{CV}$ structure of the syllables in the course of language acquisition. Some syllable structures are preferred over others. According to Macken (1995, p. 689) the acquisition evidence suggests that $\mathrm{CV}$ syllables belong to the basic inventory of phonological systems, whereas more complex syllable structures - if allowed by the

*The authors would like to thank Laura Walsh Dickey (Max Planck Institute for Psycholinguistics, Nijmegen, The Netherlands), Geert Booij (Free University of Amsterdam. Amsterdam, The Netherlands) and an anonymous reviewer for helpful comments and suggestions on the manuscript.

Address correspondence to: Niels $\mathbf{O}$. Schiller, Max Planck Institute for Psycholinguistics, P.O. Box 310, NL-6500 AH, Nijmegen, The Netherlands. Tel.; ++31/(0)24/3521-310. FAX: ++31/(0)24/3521-213. E-mail: schiller@mpi.nl 
phonotactic constraints of the language - show up later.

In speech perception, recent research has shown that sublexical units such as the syllable can be crucial in speech segmentation and recognition (Dupoux, 1993; Cutler, 1995 for a review; Mehler et al., 1981b; Nusbaum \& DeGroot 1990; Pitt \& Samuel, 1995). Using a syllable monitoring task Mehler, Dommergues, Frauenfelder, \& Segui (198Ib, p. 302) could show that French subjects were faster in detecting a sequence of phonemes when it corresponded to the first syllable of a stimulus word than when it did not. Cutler, Mehler, Norris, \& Segui (1986) could not find such an effect in English (but see also Bradley, Sánchez-Casas, \& García-Albea, 1993), but the results in Zwitserlood, Schiefers, Lahiri, \& Van Donselaar (1993) showed that Dutch listeners were sensitive to the syllabic structure of spoken words (but see also Vroomen \& de Gelder, 1994).

In automatic speech recognition systems the syllable has also proved to be a valuable unit (Fujimura, 1975; Mermelstein, 1975; Vaissière 1981). The segmentation algorithm described in Mermelstein (1975), for instance, automatically finds syllable-sized speech units because they are easier to detect than phonetic segments. Later, the syllable-sized units are further divided into individual segments.

Psycholinguistic evidence for the syllable can also be found in the area of speech production. Ih has often been claimed that segmental speech errors are sensitive to syllable structure, i.e., onsets exchange with other onsets, codas exchange with other codas, etc. (MacKay, 1970; Nooteboom, 1969; Shattuck-Hufnagel, 1979; Stemberger, 1982; but see Meyer 1992 for a review). The syllable also plays an important role in meta-linguistic tasks. Syllable constituents are one of the linguistic units that are preferably manipulated in word games (Hombert, 1986; Laycock, 1972; Lefkowitz, 1991; Bagemihl, 1995 for a review) as well as in backward talking (Cowan, Braine, \& Leavitt, 1985; White, 1955).

Under laboratory conditions certain aspects of syllable structure and syllabification have been investigated revealing further evidence for the syllable as a psycholinguistic (processing) unit (Fallows, 1981; Fowler, Treiman, \& Gross, 1993; Treiman, 1983, 1986; Treiman \& Danis, 1988; Treiman \& Zukowski, 1990; Wheeldon \& Levelt, 1995). Ferrand, Segui, \& Grainger (in press) applied (phonological) syllable priming in a word naming task. They obtained reliable facilitation in word naming only when prime and target shared the first syllable compared to the case where they shared a string of phonemes of equal length that did not form a syllable. The authors concluded that the syllable is a functional unit in word naming. In a control experiment using a visual lexical decision task, i.e., a task that could be performed without phonological encoding of the test items, the syllable priming effect disappeared. This supported the claim that the syllable priming effect arises during the creation of form representations required for overt word naming.

Crompton (1981) and later Levelt (1989) assume that there is a library of articulatory routines that is accessed during the process of speech production. Levelt and Wheeldon (1994) further develop this idea into a so-called mental syllabary. It is usually assumed that during speech production speakers first create a relatively abstract phonological and then a more detailed phonetic representation specifying the articulatory programs to be carried out. According to Levelt and Wheeldon (1994), the phonetic representations for all words (and non -words) can be assembled based on the segmental information coded at the phonological level. However, for high-frequency syllables there may be completed precompiled articulatory routines that can be retrieved as units from a mental syllabary. Levelt and Wheeldon argue that access to such a syllabary could greatly reduce the computational load relative to segment-by-segment assembly of articulatory programs.

In order to test specific claims about the role of the syllable in a given language, it is necessary to know what the syllable inventory is, and how frequent different syllable types occur. One of the reasons why syllable data are useful is, for instance, that it is possible to find out which syllable types - in terms of the CV structure predominate in a language. Typological com- 
parisons have shown that there can be large differences in the number of syllable types (Maddieson, 1984, p. 21) and in the possible CV structures (Blevins, 1995; Greenberg, Osgood, \& Jenkins, 1963) between different languages. Although the syllable inventory of a language is dependent on the phoneme inventory, the inventory of suprasegmental contrasts, and the phonotactic restrictions of the language, the relation between these variables is language-specific, i.e., the size of the syllable inventory cannot generally be predicted on the basis of, e.g., the size of the phoneme inventory or the inven1ory of suprasegmental contrasts. Rather, languages seem to differ in their phonological complexity. In an extensive empirical study, Maddieson (1984) found that the syllable inventory size did not heavily depend on the segment inventory size. In order to test this kind of claims, it is necessary to know what the syllable inventory of a language is and how frequently different syllable types occur.

The frequency of certajn syllable types and tokens can be crucial for several reasons. As has already been mentioned above, the syllable seems to be the pivotal unit in first language acquisition. It is known that infants prefer syllables that contain segments with certain places of articulation (see C. Levelt, 1994 for an overview). However, very little is known about the Irequency with which certain syllables occur. To test, for instance, the hypothesis that the child first acquires those syllable types that occur most often in her/his language, the investigator must know which syllables occur in the language and how often they are used.

For theories of spoken word recognition syllable frequencies might also play an important role. Generally, care is taken in word recognition experiments that lexeme frequencies are matched in the different experimental conditions. It might, however, atso be important to control for syllable frequencies in that kind of experiments. If high-frequency syllables behave in the same way as high-frequency words - i.e., if they are recognized faster than their low-frequency counterparts -, then frequency of syllables could contribute to the word frequency effect in spoken word recognition. In order not to confuse syllable and word frequencies, experimenters have to know the frequencies of the syllables that form part of the word forms.

In speech production, there might be articulatory differences between syllables that are highfrequency and the ones that are low-frequency. Syllables that are used more often might show less articulatory variability and a higher degree of intrasyllabic coarticulation than syllables that are less frequently articulated. To test the claim that articulatory routines exist for high-frequency syllables, one needs to know what they are.

This overview suggests that the syllable plays an important role in (psycho-) linguistic research and it appears useful to have an exact description of the syllable inventory of a language. Data on Dutch syllables is available in the CELEX lexical database (see section entitled 'Dutch Syllable inventory in CELEX'). These syllable data have two drawbacks, however. Firstly, the syllables are generated on the basis of syllabification of isolated word forms. Secondly, the lexical database for Dutch is completely based on written material, i.e., no speech is included. In connected speech, however, syliabification may deviate from the syllabification of isolated word forms. Due to phonological processes and rules such as the Onset Principle (Hoard, 1971, p. 137; Kahn, 1976; Selkirk, 1982, p. 359), which is highly productive in connected speech, syllables without a consonantal onset are unlikely to be produced. In CELEX only those phonological rules that take the prosodic word as their domain had an impact on the resulting syllables. Effects of connected speech such as vowel reduction in unstressed syllables due to articulatory undershoot (Lindblom, 1963), gestural blending and hiding (Browman \& Goldstein, 1989), higher level phonological processes (Booij, 1995) such as assimilations, external sandhi (plus subsequent resyllabifications), cliticizations, and other effects that typically can be found in allegro style or informal speech had no influence on words or syllables in CELEX. It is known that there are a number of phonological rules that apply in connected speech and modify the form of the words and - consequently - of their syllables. Therefore, it is desirable to have data about syllables in connected speech. 
The present study gives an indirect estimation of what might happen to syllables in connected speech. To investigate this question, a large newspaper corpus was transcribed phonemically, processed by the rules of word phonology, and syllabified by means of a computer program. The output resulted in a set of word level syllables (hereafter lexeme syllables). These lexeme syllables were compared to the CELEX syllable data. Then, an additional set of higher level phonological rules were applied to the same corpus yielding potential syllables of connected speech (hereafter speech syllables). The two sets of syllables were compared in terms of their CV structures, their segmental make-up, and their token frequencies. The comparison shows how lexeme and speech syllables differ. Furthermore, information about the frequency of application of phonological rules in Dutch is provided. The implications of this empirical investigation for psycholinguistic research are discussed.

\section{THE SYLLABLE IN DUTCH}

Generally, the syllable structure of a language can be defined on the basis of a syllabic CVtemplate (Itô, 1986, 1989) that specifies the maximal number of $\mathrm{Cs}$ in the onset, of $\mathrm{Vs}$ in the nucleus, and of $\mathrm{Cs}$ in the coda, i.e., the prosodic shape of the maximal syllable. According to Trommelen (1984) and van der Hulst (1984) the syllable template for Dutch can be filled with two $\mathrm{Cs}$ in the onset plus an additional $\mathbf{C}$ called the syllabic prefix, which can only be /s/ (Booij, 1995, p. 26), two Vs in the nucleus (where $V$ represents a short vowel and VV either a long vowel, a diphthong, or a schwa'), and two Cs in the coda plus an additional $\mathrm{C}$ in the appendix if a syllable stands in word final position. Exceptionally long codas can have four $C$ positions if they are word-final and follow a short vowel (e.g., 'herfst' /herfsu ('autumn')). Together, nucleus and coda form the rhyme, which may consist of at most three positions. There are,

I. Schwa $(/ 2 /)$, although phonetically short, patterns phonologically with the long vowels in Dutch (Booij, 1995; Kager, 1989; Kager \& Zonneveld, 1986: Trommelen, 1984). however, a few exceptionally long rhymes (e.g. 'twaalf' /walf/ ('twelve')) that can have four positions (Booij, 1995, p. 26).

The syllable template alone does not adequately describe the facts about syliables, however (Selkirk, 1982). In addition to the template. a set of phonotactic constraints (collocational restrictions) is necessary to state which syllables are possible in Dutch. Long vowels, for insance. cannot be followed by a C-cluster consisting of a sonorant plus a non-coronal obstruent (Kager, 1989). It is generally claimed that the co-occurrence restrictions are stronger between nucleus and coda than between the onset and any of the other syllable constituents (Kuryłowicz, 1948: Bell \& Hooper, 1978; but see Davis, 1982\}.

Clements (1990) distinguished a syllable core from extrasyllabic elements. According to him. a process of core syllabification which is sensitive to sonority constraints precedes the syllabification of extrasyllabic elements. While core syllables respect the Sonoriry Sequencing Generalization (SSG) (Selkitk, 1984), surface syllables may contain syllabic afïixes, i.e., extrasyllabic consonants that often violate the SSG. Extrasyliabic segments therefore have to be described separately (e.g., in the form of auxitiary templates as suggested in Selkirk, 1982). In Dutch, a core syllable can have five $X$-slots al maximum, i.e., two Cs in the onset and either VCC or VVC in the thyme. Surface syllables can have additional $C s$ in onset and coda.

Monomorphemic Dutch words are syllabified in accordance with the Onset Principle. There is, however, one problematic case for the syllabification in Dutch. It is generally assumed that a Dutch syllable cannol end in a short vowel (see Booij, 1995, p. 25; Trommelen, 1984. p. 83; van der Hulst. 1984, p. 102-104: Lahiri \& Koreman, 1988, p. 221; Kager, 1989,.- That is

2. Kager $(1989$, p. 192) summarizes the arguments lor this claim. First, short vowels are absent from word final positions. A generalization of this would state that short vowels do not appear in the final position of any syllable. Second, short vowels cinnot occupy prevocalic positions, i.e., they cannot occur in hiatus. A third argument comes from stress assignment. ln words like "Armageddon' stress shilts from the (regularly stressed) antepenult to the penult. This. however, presupposes that the penull is it toloced syl. 
why a single intervocalic consonant cannot occupy the onset position of the following syllable although this would normally have to be the case according to the Onset Principle. Thus, in cașes like 'lekker' /lekər/ ('tasty'), the / $/$ cannot be the coda of the first syllable because this would contradict the Onset Principle. But it cannot be the onset of the second syllable, either, because open short vowel syllables are not allowed (for reasons mentioned above). Neither can $/ \mathrm{k} /$ be a geminate (i.e., /kk.kər/) because geminates are not allowed within a prosodic word (Booij, 1995, p. 68). One way to account for the (phonological) syllable affiliation of $/ \mathrm{k} /$ is to assume that it is ambisyllabic, i.e., it belongs to both syllables without being represented (or produced) twice (see Ramers, I988, p. 5I; Vennemann, 1982, p. 280 , 1994, p. 23 for ambisyllabicity in German). This view is adopted in the present paper.

\section{THE DUTCH SYLLABLE INVENTORY IN CELEX}

\section{Phonetic Transcription}

CELEX is a lexical database that provides syntactic, morphological, phonological, orthographic, and frequency information about Dutch, English, and German word forms. The lemma list for Dutch is based on two different dictionarjes $^{3}$ and on a large text corpus of the Institute

lable that contains a full vowel. This can only be the case if the single intervocalic consonant, i.e., the $/ d /$ closes the syllable. Due to the fact that the Onset Principle has a rather strong status in Dutch and that the $/ \mathrm{d} /$ does not devoice, which should be the case in syllable-final position, we can assume that the $/ d /$ is more likely to be ambisytlabic than a single coda consonant.

In spite of these phonological arguments, it has been shown in a recent experimental study by Schiller, Meyer and Levelt (submitted) that native speakers of Dutch to a certain extent do produce open syllables containing short vowels. We suggest that these facts can be accounted for in terms of Optimality Theory. The closing of short vowel syllables is not a categorical rule but rather a highly ranked constraint that can be violated.

3. Sterkenburg, P.G.J, van et al. (1984), Van Date groot worrdenhoek van hedendaags Nederlands. Utrecht, Antwerpen: Van Dale Lexicografie. for Dutch Lexicology (INL) ${ }^{4}$. The INL text corpus was also used to determine the word form frequencies in CELEX. According to Burnage (1990) the INL corpus is made up of many different contemporary texis, but spoken language is not included. The phonological form of the entries in the CELEX word form lexicon is represented by a transcription format called DISC that represents each segment by one symbol. The transcription criteria are not strictly phonological. According to the Dutch Linguistic Guide for CELEX, the transcriptions are phonetic for the most part (Burnage, 1990). It seems to be most appropriate to speak of an abstract, prototypical phonetic transcription such as the one given in a dictionary. This seems to be confirmed by the set of phonological rules that were applied in CELEX. Nasal assimilation, for instance, is a phonetically motivated rule that changes an underlying nasal into its phonetic surface realization (e.g., 'aanbieden' ('to offer') /an.bi.dən/ -> /am.bi.dən/). The same is true for progressive and regressive voice assimilation, two phonological rules that also yield phonetic surface representations and have been applied in CELEX. All these rules were restricted to word phonology. The general impact of the phonological rules on the Dutch word forms - and hence on the syllables - is described in the next section.

\section{Application of Phonological Rules}

In Dutch, there are quite a number of word and sentence phonology rules. These rules have different segmental effects on the word forms to which they apply. Three different kinds of rules have to be distinguished with respect to the domain of application: First, there are rules that only apply at the word form level, e.g., all kinds of morphophonemic rules and final devoicing. Second, there are rules that can apply both on the word and on the sentence level (for the differentiation between word and sentence level see Booij, 1995). Most often, these rules are obligatory on the word level, whereas they are

Woordentijst van de Nederlandse tual (1954), 's-Gravenhage: Staatsdrukkerij- en Uitgeverijbedrijf.

4. INL is the abbreviation of Instituus voor Nederlandse Lexicologie. 
optional on the sentence level. Among these rules are voice assimilations (regressive and progressive), nasal assimilation, $/ \mathbf{n}$-deletion, degemination (and cluster simplification in general). Third, there are rules that can only apply on the sentence level because their domain of application spans more than one (grammatical) word, e.g., external sandhi, fusions, and cliticizations. In CELEX the first two types of rules have been applied, rules of the second type only on word level. In particular, the rules applied to the word forms in CELEX comprise final devoicing, voice assimilation, nasal assimilation, hiatus rules, and degemination.

The rule of final devoicing applies at a level that is called the word level, e.g., an intermediate level between lexical and postlexical level in the framework of lexical phonology (Booij, 1995; Booij \& Rubach, 1987; Kenstowicz, 1994; Kiparsky, 1985; Mohanan, 1986). Final devoicing applies after all morphological rules have appiied. It changes all syllable-final voiced obstruents into their voiceless counterparts. Voice assimilation rules are fed by final devoicing, i.e., they apply after all final obstruents have already been devoiced (Slis, 1984; Zonneveld, 1983). Progressive voice assimilation devoices voiced fricatives if they are preceded by another voiceless obstruent. The rule of regressive voice assimilation voices voiceless obstruents followed by a voiced stop. In accordance with the Elsewhere Principle (Kiparsky, 1973, 1982) progressive voice assimilation, being more specific, takes precedence over regressive voice assimilation because the former rule is more specific and blocks the application of the latter. Two hiatus rules have the effect of avoiding the clash of two adjacent vowels. Either a consonant is inserted between the two vowels (homorganic glide insertion), or the first of the vowets - if it is a schwa - is deleted (prevocalic schwa deletion). Degemination has the effect of deleting one of two adjacent, identical consonants. A geminate is reduced to a simple consonant. An overview of these phonological rules and their segmental effects is given in Table 1.

In CELEX, these phonological rules have been applied to all word forms, i.e., the effect of these rujes is represented in the phonetic transcriplions that represent the phonological surface structure of the word forms. These phonetic transcriplions have been syllabilied to yield the Dutch syllables. The syllable data in CELEX are the result of a syllabification algorithm documenIed in van der Hulst and Lithiri (ms). The rules of syllabification applied in CELEX comprise two parts, core syllabification and stray adjunc-

Table I. Phonological Word Level Rules in Dutch and their Phonological Effects.

\begin{tabular}{|c|c|c|c|}
\hline \multirow[t]{2}{*}{ Phonological rule } & \multirow[t]{2}{*}{ Example } & \multicolumn{2}{|c|}{ Phonological effect } \\
\hline & & underlying form & surface form \\
\hline final devoicing & "hond' (dog) & thondf & |hont| \\
\hline $\begin{array}{l}\text { progressive voice } \\
\text { assimilation }\end{array}$ & 'handzaam' (handy) & $\begin{array}{l}\text { flondzam/ } \\
\text { (/hantzam/) }\end{array}$ & |hontsam| \\
\hline $\begin{array}{l}\text { regressive voice } \\
\text { assimilation }\end{array}$ & 'handbal' (bandball) & $\begin{array}{l}\text { /hondbal/ } \\
\text { (/hontbal/) }\end{array}$ & |handball \\
\hline nasal assimilation & 'winkel' (shop) & Iwinkal/ & \{wiljkal\} \\
\hline $\begin{array}{l}\text { homorganic glide } \\
\text { insertion }\end{array}$ & 'bioscoop' (cinema) & /bioskop/ & |bijoskopl \\
\hline $\begin{array}{l}\text { prevocalic schwa } \\
\text { deletion }\end{array}$ & 'codeer' (coder) & /kodəer/ & |koder| \\
\hline degemination & ‘jk kan' (I can) & /ik kan/ & |jkan| \\
\hline
\end{tabular}

Note. The form in parentheses reflects the phonological status of the word form after final devoicing has applied. 
tion. During core syllabification, vowels and consonants are parsed into syllables respecting the constraints of the Dutch core syllable template explained above. Following the Onset Principle, as many consonants as allowed by the core syllable template are attached to the left of a syllable nucleus, i.e., to the onset. Word forms are parsed from left to right, i.e., starting with the first syllable of a word. Single intervocalic consonants following short (lax) vowets are made ambi.yyllabic. Stray consonants, i.e, consonants that could not be attached to a syllable onset, are syllabified in the second step called stray adjunction. During stray adjunction unsyllabilied consonants are allached to the syllable onset il they are either word initial or if they conslitulc an /s/ followed by a voiceless plosive. Oherwise stray consonants are attached to the coda ot the preceding syllable. Syllable frequencies were calculated by summing up all the 10ken frequencies of the word forms in which a particular syllable occurred (Piepenbrock, p. c.).

\section{PREPARATION OF THE CORPUS}

The syllabification in CELEX is based on isolated word forms. As we have already mentioned above. the corpus on which the CELEX lexical database for Dutch is based consisted of two dictionaries, i.e., word lists, and a large text corpus, i.e., a running lext. However, this running text was parsed into a list of word forms, which then was taken to determine word and syllable frequencies. Hence, although CELEX was parlially based on at running lext, the syllabificalion was restricted to isolated word forms.

Thus, it is nol clear how well the syllables in (IELEX correspond in the sylables in acual cunnected speceh. It is possible, for instance, lhat a higla-frequency syllable in CELEX is acually hardly ever realized hecause it only appars as a clitic in connected speech (e.g.. "het" /hel/). or that a low-frequency syllable in CELEX is high-frequency in connected speech because one or more other syllables change into that syllable due to higher level phonological processes. To investigate the differences between syllables from an isolated word list and from connected speech, a Dutch newspaper corpus of approximately five million word forms was transcribed in phonemic form (DISC notation), processed by a set of phonological rules, and then syllabified by means of the CELEX syllabification algorithm. This corpus comprised 85 issues of the Dutch newspaper 'TROUW' containing 4,863,212 word form tokens in total. The TROUW corpus can be characterized as a contemporary, running text sample of written Dutch. The set of rules comprised the phonological rules that were also applied in CELEX. The resulting set of lexeme syllables from the TROUW corpus was compared to a resampled (lexeme) syllable list of CELEX. In a second step, higher level rules were applied to the TROUW corpus in order to simulate a connecled speech condition. The resulting set of potential connected speech syltables was compared to the lexeme syllables from TROUW in order to investigate differences between the two kinds of syllables. The impact of the higher level phonological rules is demonstrated by the frequency of their applications and by the segmental analysis of the speech syllables.

In order to compare the lexeme syllabies and the speech syllables, the TROUW corpus had to be uanscribed and syllabified. This was done automatically by means of several computer programs described below." The processing of the corpus consisted of three parts, phonemic transcription of the text (grapheme-to-phoneme mapping), application of phonological rules, and syllabification. Care was taken that the latter two steps were carried out in the same way as for CELEX.

\section{Phonemic Transeription}

The phonemic transcription program can be characterized as a grapheme-to-phoneme mapper for Dutch using the DISC transcription notation.

5. All numbers that occurred in the texts were deleted. Also. the attempt was mate to delete all proper names and foreign words hut not isll of them coutd be detected automatically. The whole retnaining text was sel to lowet case characters.

6. All computer programs tsed in the empirical investigation reported in this paper were written in the ":Iwk" programming language and run on UNIX machines. 
Dutch orthography is relatively transparent as compared to English or German orthography. The general rule that applies in the spelling of Dutch vowels is that long vowels are spelled as single letters in open syllables (including wordfinal position), and as geminates in closed syllables. There are some problematic cases, however, in particular the grapheme $\langle\mathrm{e}\rangle$, which can correspond to $/ e /, / \varepsilon /$, or $/ \% / .{ }^{7}$ In CELEX accuracy is probably very high because problematic cases like the transcription of $\langle\mathrm{e}\rangle$ are resolved in a rather secure way: many words were transcribed by hand.

\section{Application of Phonological Rules}

The second step was to modify the phonemically transcribed words of the TROUW corpus by applying the word-level phonological rules of Dutch. Because there is some degree of abstractness in the Dutch spelling, and in particular the effects of morpholexical rules are always re-

7. The grapheme $<e>$ represents the long closed vowel /e/. But short open $/ \mathrm{e} /(/ \varepsilon /)$ and schwa $(/ \mathrm{a} /)$ are also represented by that grapheme. As a consequence, in open syllables <e> can either be $/ e /$ or $/ 2 /$ (e.g.. /re.dok.si/ 'redactie' vs/ba.lop/ 'beloop') and in closed syllables 〈e> can either be /e/ or / / / (e.g., /per.son/ 'persoon' vs /var.volx/ 'vervolg'). This depends on whether <e> betongs to the root (as in 'redactie') or is part of an affix (as in 'beloop'). As the mapper used hardly any morpholexical information the program could not correctly transcribe all the $<e>s$. The general rules for the transcription of <e> were the following: in open syllables, $\langle\mathrm{e}\rangle$ was recognized as a long vowel and transcribed as / $\mathrm{e}$, whereas in closed syllables it was transcribed as $/ \varepsilon /$. Word-final $\langle e\rangle$ represents schwa because long $/ \mathrm{e} /$ is marked by a vowel geminate, i.e., <ees, at the end of a word. <ee> was always transcribed as $/ \mathrm{e} /$ except for the indefinite article ('een') where <ee> equals a schwa phonologically. The additional transcription rules relate to diminutive forms ( $\langle\mathrm{e}\rangle->/ \partial /$ ) and the pretixes 'be-" and 'ge-". If the strings 'be' and 'ge' were recognized as prefixes, then they were transcribed with schwa. Nevertheless, some <e>s are incorrectly transcribed as $/ \mathrm{e} /$ or $/ \mathrm{g} /$ (when $<$ e $>$ represented a schwa in fact), whereas the reverse case was unlikely to occur. Thus the frequencies of syllables with either $/ \mathrm{e} /$ or $/ \varepsilon /$ as nuclei are overestimated, whereas schwa syllables are underestimated. Although the grapheme $<e>$ has a high token frequency and the error rate in the iranscription of $<e>$ was relatively high, the accuracy of the grapheme to phoneme mapping program reaches more than $98 \%$ as could be determined for a sample of 1000 words. flected in the orthography, of. Booij (1995, p. 185), morpholexical and allomorphic rules did not have to be applied to the transcribed word forms. By contrast, pure phonological rules of the word level are not necessarily reflected in the spelling. They are obligatory and have to be applied to the transcribed word forms. Care was taken that exactly the same rules were applied as in CELEX as documented in van der Hulst and Lahiri (ms): syllable-final devoicing. progressive and regressive voice assimilation, nasal assimilation, degemination and hiatus rules (homorganic glide insertion, prevocalic schwa deletion).

The phonological rules were implemcited in the form of a computer program. They were then applied automatically to the TROUW corpus, i.e., every transcribed word form underwent them. The result of this second step was that all the phonemically transcribed word forms of the TROUW corpus were phonologically modified if they mel certain structural conditions. The retative frequency of application of the rules (per one million word forms: rounded numbers) are given in Table 2 .

As can be seen in Tabie 2, syliable-ijnal dcvoicing has a high lrequency of applicalion cornpared to the other two voice assimilation rules. The high frequency of application of the degemination rule is due to a characteristic of Duch spelling. Single intervocalic consonants are geminated after short (lax) vowels. The degeminition rule deletes the first $C$ of a geminate $\mathrm{k}$ yield the phonemic representation. Therefore. it is important to note that degemination is a spelling-to-sound rule within words. 1301 a plosnological rule. Only between words degemination is a phonological rule in Dutch.

\section{Syllabification}

In order to compare syllables from the TRO) IW corpus and from the CELEX lexical databasc with each other, the word forms lrom the TROUW corpus had to be syllabitied according to the same syllabification algosithn. (One prohlem for the implementation of the syllatbitication algorithm in TROUW was the Onsel Principle. In order to generate correct syllable onsets using onset maximization we had to imple- 
Table 2. Relative Frequency of Application of Phonological Rules on the Word Level.

\begin{tabular}{|c|c|c|}
\hline phonological rule & $\begin{array}{c}\text { frequency of application } \\
\text { (per one million word forms) }\end{array}$ & segmental effect \\
\hline syllable-final devoicing & 57,030 & $\begin{array}{c}\mathrm{b}, \mathrm{d} / l>/ \mathrm{p}, \mathrm{y} / \\
/ \mathrm{z}, \mathrm{v}, \mathrm{v} />/ \mathrm{s}, \mathrm{f}, \mathrm{x} /\end{array}$ \\
\hline progressive voice assimilation & 5,699 & $/ 2, \mathrm{v}, \mathrm{y} / \rightarrow / \mathrm{s}, \mathrm{f}, \mathrm{x} /$ \\
\hline regressive voice assimilation & 13,971 & $\begin{array}{l}/ \mathrm{s}, \mathrm{f}, \mathrm{x} / \rightarrow>/ \mathrm{z}, \mathrm{v}, \mathrm{v} / \\
/ \mathrm{p}, \mathrm{l}, \mathrm{k} / \rightarrow / \mathrm{b}, \mathrm{d}, \mathrm{g} /\end{array}$ \\
\hline nasal assimilation & 38,224 & $/ \mathrm{n} / \rightarrow / \mathrm{g}, \mathrm{n}, \mathrm{m} /$ \\
\hline degemination & 97.284 & 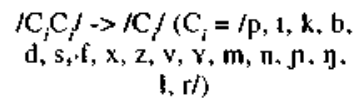 \\
\hline
\end{tabular}

sum

212,208

ment phonotactic constraints on onsets. To do so, we provided the syllabification algorithm with a list of possible syllable onsets in Dutch. This had the drawback that word-internal codas could be drawn into the onset of the following syllable. For instance, in a word form like "kalfsleer" $/$ kalfsler/ ("caltskin"), which consists of the morpheme 'kalf' ("calf'), the linking morpheme ' $s$ ", and the morpheme 'leer' ('skin'), the syllable boundary falls between the last two morphemes, i.e.. $/ \mathrm{kalfs}$.ler/. But due to the fact that $/ \mathrm{s}$ / is a possible onset in Dutch, our program would syllabify the word as $/ \mathrm{kalf}$.sler/following the Onset Principle.

The syllabification algorithm was also implemented in a computer program. The computer program was applied to the whole set of phonemicalty transcribed and phonologically modified word torms. The result was a fully syllabified. phonemically transeribed, and phonologically moditied text.

The syllable types of this corpus were listed, and their loken trequencies were calculated. Due to idiosyncracics of the corpus (abbreviations, acronyms, non-native word forms, proper names, etc.) 'odd' syllables emerged that were not wellformed and therefore had to be filtered out. For instance, there were 294 syllable types without any nucleus, I I syllable types with more than one nucleus and 639 syllable types with nuclei that were 100 long (more than two $\mathrm{V}$-positions). in tolal, ill-formed syllables amounted to $7.28 \%$ of all generated syllable types.
An interesting secondary result was discovered during the statistical analysis of the syllable data in CELEX. The calculation of the cumulative frequency distribution revealed that $85 \%$ of all syllable tokens in Dutch can be covered by the 500 most frequent syllables, i.e.. less than $5 \%$ of the syllable types. This finding is important for the notion of a mental syllabary as it makes the idea of a separate store for highfrequency syllables in terms of their articulatory motor programs very attractive.

\section{Evaluation of the Lexeme Syllables from TROUW}

The TROUW corpus is smaller than the corpus underlying CELEX, and the transcription and syllabification in the present study was less sophisticated than those used in setting up the CELEX data base. Analyses were carried out to determine how closely the two syllable samples corresponded with each other. Only if the TROUW syllable inventory closely resembles the CELEX inventory, and therefore is Jikefy to be a representative sample of Dutch lexeme sylIables. the further analyses - the investigation of the effects of sentence-level phonotogical rules - can be of any use.

Table 3 presents a number of summary statistics for our counts of syllables in the CELEX and TROUW corpora. The first three rows of the leftmost column list the number of tokens $(N)$, the number of types ( $V)$, and the mean syllable frequency $(N / V)$ in the CELEX lexical da- 
Table 3. Summary Statistics for Syllables in CELEX and TROUW.

\begin{tabular}{|c|c|c|c|c|}
\hline & $\begin{array}{l}\text { CELEX } \\
\text { (all) }\end{array}$ & $\begin{array}{l}\text { CELEX } \\
\text { (sample) }\end{array}$ & $\begin{array}{l}\text { TROUW } \\
\text { (CLX: all) }\end{array}$ & $\begin{array}{c}\text { TROUW } \\
\text { (CLX: sample) }\end{array}$ \\
\hline$N$ & $63,906,898$ & $7,801,701$ & $7,339,860$ & $7,339,860$ \\
\hline$v$ & 9.264 & 8,341 & 12,027 & 12,027 \\
\hline$N / V$ & $6,898.4$ & 935.3 & 610.3 & 610.3 \\
\hline median & 144.5 & 26 & 8 & 8 \\
\hline$N_{u}$ & $2,588,403$ & 316,453 & 280.283 & 288,994 \\
\hline$v^{u}$ & 2,521 & 1,951 & 5,284 & 5,637 \\
\hline$N_{N} / V_{u}$ & $1,026.7$ & 162.2 & 53.0 & 51.3 \\
\hline median. & 21 & 5 & 2 & 2 \\
\hline$N_{u} P$ & $4.05 \%$ & $4.06 \%$ & $3.82 \%$ & $3.94 \%$ \\
\hline$V_{*}^{\prime \prime} P$ & $27.21 \%$ & $23.39 \%$ & $43.93 \%$ & $46.87 \%$ \\
\hline$N_{b}$ & $6 \mathrm{I}, 318,495$ & $7,485,248$ & $7,059,577$ & $7,050,866$ \\
\hline$v_{b}^{b}$ & 6,743 & 6,390 & 6,743 & 6,390 \\
\hline$N_{b} N_{b}$ & $9,093.7$ & $1,171.4$ & $1,046.9$ & $1,103.4$ \\
\hline median & 300 & 44 & 31 & 36 \\
\hline$N_{\mu} P$ & $95.95 \%$ & $95.94 \%$ & $96.18 \%$ & $96.06 \%$ \\
\hline$V_{*} P$ & $72.79 \%$ & $76.61 \%$ & $56.07 \%$ & $53.13 \%$ \\
\hline
\end{tabular}

Note. $N$ : number of tokens; $V:$ number of types; median: median syllable frequency. $N_{u}:$ number of tokens unique to corpus; $V_{u}$ : number of types unique to corpus; median $_{u}$ : median frequency for unique syllables; $N_{u} P: N_{\mathfrak{H}} / N ; V_{u} P: V_{d} N$.

$N_{b}$ : number of tokens in both CELEX and TROUW; $V_{b}$ : number of types in both CELEX and TROUW; median $_{b}:$ median frequency for shared syllables; $N_{b} P: N_{b} / N ; V_{b} P: V_{b} N$.

tabase. The third column lists the corresponding statistics for the syllables in the TROUW corpus. The number of syllable tokens in CELEX, approximately 64 million, is much larger than the number of syllable tokens in TROUW, approximately 7 million. This is to be expected, as the CELEX counts are based on a corpus of 42.38 million word forms, while the TROUW corpus contains only $\mathbf{4 . 8 6}$ million words. In spite of this difference in size, the TROUW corpus contains more syllable types $(12,000)$ than CELEX $(9,000)$, so that the mean syllable frequency in CELEX, 6898.4, is much larger than the mean syllable frequency in TROUW, which is 610.3 .

Does this large difference in mean syllable frequency imply that our syllabification algorithm is unreliable, in that it leads to an overly large number of syllable types for the TROUW corpus? Has the syllabification algorithm produced large numbers of spurious syllable types? To answer these questions, it is necessary to consider in some detail the consequences of the difference in sample size between the CELEX corpus and the TROUW corpus.

It is well known in word frequency statistics that the highly skewed nature of lexical frequency distributions and the large probability mass of unseen types substantially affects sample estimates (see, e.g., Good, 1953; Chitashvili \& Baayen, 1993). Figure 1 shows how severely a point estimator such as the arithmetic mean can be affected. To produce this figure, we randomly sampled (without replacement) increasingly large numbers of word tokens (1 million, 5, 10, 15 , ..., 40 million) from CELEX. For each sample, we counted the number of different syllables and the mean frequency of these syllables. Figure 1 plots the increase in number of syllables ( $V s$, solid line) and the mean syllable frequency $\left(N_{s} / N_{s}\right.$, dotted line) as a function of the number of word tokens $(N w)$ in the sample. As expected, the number of different syllable types increases as the size of the corpus increases. As we continue sampling more words, more and more previously unseen syllables appear, many 


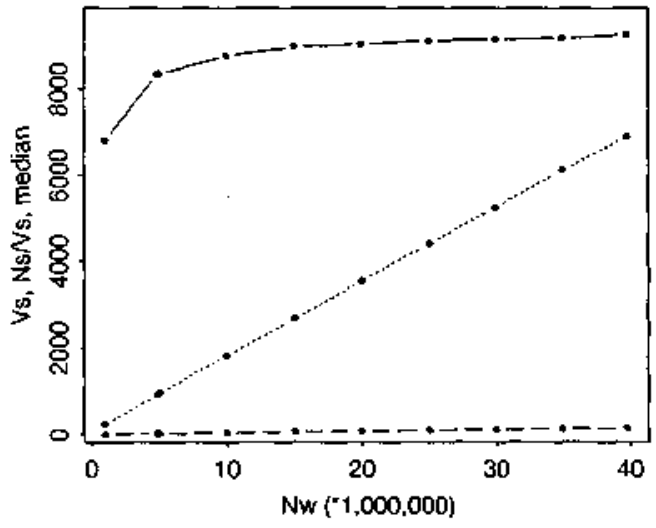

Fig. I. Plot of the number of syllable types $V s$ (solid line), mean syllable frequency $N s / V s$ (dotted line) and median syllable ftequency (dashed line) as a function of corpus size.

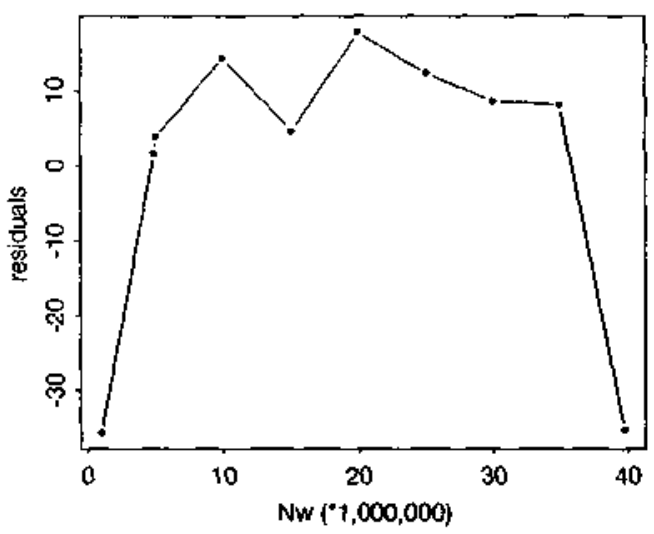

Fig. 2 Plot of the residuals of a linear fit to $N_{s} N s$.

at first, fewer and fewer as the sample becomes larger.

Interestingly, the mean syllable frequency increases as the corpus size in words is increased. (The increase in mean syllable frequency looks linear to the eye, but the residuals of a linear fit plotted in Figure 2 reveal that a non-linear development is masked by the huge sample sizes involved.)

A steady increase in the mean as a function of the number of observations does not occur for normally distributed random variables, for which the precision with which the mean is estimated increases with the number of observations, but for which the estimate of the mean itself is more or less constant. But for skewed distributions with high-frequency outliers, the pattern observed for the mean syllable frequency can easily occur.

Table 4 presents an artificial example with one high-frequency outlier with a fixed probability of 0.99 . The remaining $1 \%$ of the tokens represent a number of types that, as is the case for the syllables in CELEX, increases rapidly at first, but increases less rapidly as the sample size increases. The resulting mean increases roughly linearly, as shown in Figure 3.

Given that in our CELEX data some $5 \%$ of the types account for roughly $85 \%$ of all tokens, i.e., with the 500 most frequent syllable types in CELEX you can construct $84.75 \%$ of all syllable tokens, the strong effect of skewness in Figure 1 is easily understood. The dashed line in Figure I shows that the median is not affected to the same extent as the mean by the outlier structure. Nevertheless, the median is not constant, but increases significantly $(r=0.999, p<$ .0001 ) from 10 at 1 million words to 144.5 in the full corpus. This suggests that it is not only the outlier structure, but a more general overall skewness in the frequency distribution that is at issue.

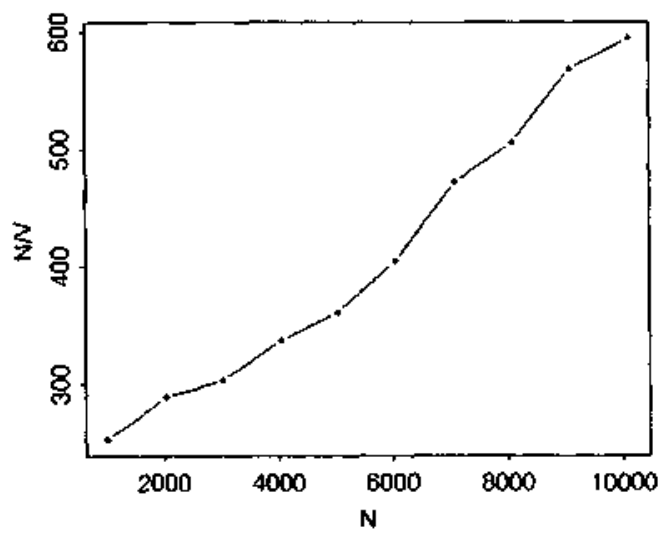

Fig. 3. Plot of the effects of outliers on the mean for at hypothetical example. 
Table 4. Hypothetical example of the effects of outliers on the mean for decreasing growth rate of the number of types $(V)$.

\begin{tabular}{lccc}
\hline$N$ (outlier) & $N$ (other) & $V$ & $N / N$ \\
\hline 1000 & 10 & 4 & 252.5 \\
2000 & 20 & 7 & 288.6 \\
3000 & 30 & 10 & 303.0 \\
4000 & 40 & 12 & 336.7 \\
5000 & 50 & 14 & 360.7 \\
6000 & 60 & 15 & 404.0 \\
7000 & 70 & 15 & 471.3 \\
8000 & 80 & 16 & 505.0 \\
9000 & 90 & 16 & 568.1 \\
10000 & 100 & 17 & 594.1 \\
\hline
\end{tabular}

Note. $N$ (outlier): frequency of outlier type

$N$ (other): summed frequencies of non-outliers

$V$ : number of different types

$N / N$ : mean frequency

In order to eliminate those differences between the CELEX and TROUW corpora that arise due to a difference in sample size, we selected a random sample (without replacement) of 4,863,212 word tokens (the number of word tokens in the TROUW corpus) from CELEX, and used this CELEX sample to calculate sizeadjusted estimates of the number of syllable types and tokens. The results are summarized in the second column of Table 3 . The number of syllable tokens in the two samples is now of the same order of magnitude $(7.8$ million for the CELEX sample, and 7.3 million for the TROUW sample). The mean and median syllable frequencies have also become more similar, but both mean and median are still substantially higher in the CELEX sample than in the TROUW cor* pus (935.3 and 26 for CELEX, 610.3 and 8 for TROUW). Closer examination of the syllables in the two samples reveals that this difference is largely driven by the syllables that appear in the TROUW corpus only.

The middle section of Table 3 summarizes the frequency distributions of those syllables that are unique to the CELEX and TROUW corpora. Restricting ourselves to the CELEX sample and the TROUW data compared to this sample (the column labeled TROUW CLX: sample), we find that $23.39 \%$ of the syllable types in the CELEX sample do not occur in TROUW. These syllables, however, account for only $4 \%$ of the syllable tokens in the CELEX sample. In the TROUW corpus, $43.93 \%$ of the syllables do not occur in the CELEX sample, but again these types represent only $4 \%$ of the tokens in TROUW. This suggests that there is a large number of very low-frequency syllables in TROUW that are the result of incorrect transcription and/or syllabification. Assuming that both the CELEX sample and the TROUW sample would have approximately the same number of unique real syllables, we can estimate the number of spurious syllables in the TROUW corpus by subtracting the number of syllables unique to the CELEX sample (1,95!) from the number of syllables in the TROUW sample $(5,637): 5637-1951=3686$. Thus, more than half of the syllable types in TROUW may be suspect. Fortunately, the accuracy of our syllabification algorithm is reasonable token-wise: only $4 \%$ of all tokens in TROUW do not occur in the CELEX sample, for the remaining $96 \%$ of the tokens, we may have some confidence that our analyses are reliable.

This conclusion is supported by a comparison of the syllables that appear in both the CELEX sample and the TROUW sample. The third section of Table 3 shows that the mean and median frequencies of the 6,390 syllables common to both samples are quite similar $(1,171,4$ and 44 for CELEX, 1,103.4 and 36 for TROUW). Inspection of the correlation structure reveals a similar pattern. Figure 4 plots the log (syllable frequency +1 ) for the syllables in the CELEX sample and TROUW. The syllables unique to CELEX are represented on the line $Y$ $=0$, the syllables unique to TROUW are represented on the line $X=0$. Since the scatterplot reveals a heteroskedastic pattern, we have used a non-parametric correlation test (Spearman rank) to ascertain the extent to which the syllable frequencies are correlated. For the join of all syllables in both samples, $r_{s}$ equals $0.419(p<.0001)$, for the syllables common to both samples, $r_{s}$ is $0.821(p<0.0001)$. It is clear that for the higher frequency syllables, the correlations are robust, but that for the lower frequency ranges the correlations become increasingly weaker.

Summing up, our comparison of syllable frequencies according to CELEX and TROUW 


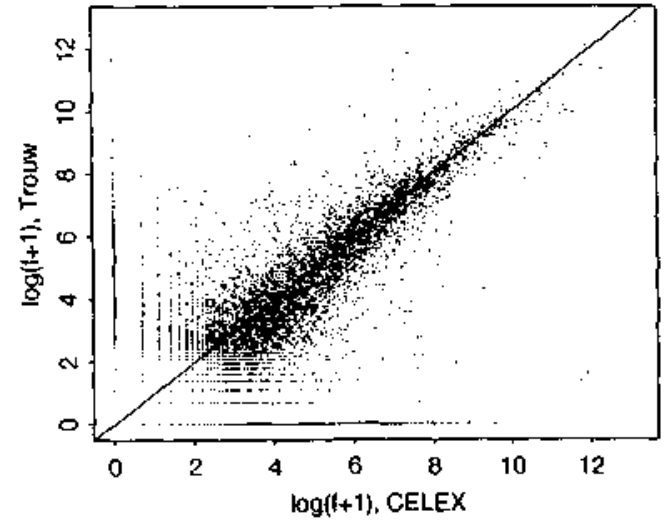

Fig. 4. Scatterplot of log(syllable frequency +1 ) for CELEX and TROUW, visualizes the correlation between the syllable frequencies in the two corpora.

shows that our simple syllabification algorithm is reasonably reliable for token-based analysis with an etror rate of less than $5 \%$, but that for type-based analysis a substantial number of possibly spurious syllables has been generated.

\section{SPEECH SYLLABLES IN TROUW}

\section{Application of Sentence-level Rules}

As already mentioned, for some research questions it might be interesting to know whether the lexeme syllables of a language give a good estimation of those syltables that appear at a phonetic surface level in connected speech, i.e., of the speech syllables. If word forms are uttered in a linguistic context, many phonologica] rules of connected speech apply (above the isolated word level) which can aiter the phonetic form of a word, and of its syllab]es (see Introduction). To test whether the lexeme syllables and their token frequencies give a good estimation of the syllables and their corresponding token frequencies in connected speech, the potential connected speech syllables were generated from TROUW. The reason why we could not generate speech syllables from CELEX but had to use a new corpus was that the INL text corpus, on which the Dutch lexical database of
CELEX is based, is not directly accessible via CELEX.

To obtain the speech syllables, the following set of connected speech sentence-level rules were applied to the transcribed and syllabified TROUW corpus: progressive and regressive voice assimilation, nasal assimilation, C-cluster simplification (including degemination), $/ \mathrm{n} /$ -deletion, external sandhi, and different fusions and cliticizations. Some of these rules had already been applied on the word level. On the sentence level they can apply again if the necessary structural conditions are met between word boundaries. Other rules can only apply on a higher level, e.g., external sandhi (Nespor \& Vogel, 1982; Stroop, 1986; Vogel, 1986), fusions, and cliticizations (Berendsen, 1986; Booij, 1995). They often have the effect of shifting syllable boundaries. Such resyllabification occurs whenever a word form ending in a consonant is followed by a word form beginning with a vowel. In accordance with the Onset Principle, the coda consonant is shifted to the onset of the following syllable yielding a resyllabification (e.g.,

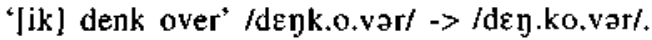
In Dutch, resyllabification blocks $/ \mathrm{n} /$-deletion, e.g., 'vragen over' becomes/vra. zano.var/ because $/ \mathrm{n} /$ only deletes in coda position. Cliticization attaches function words to their host words if the former occur in their weak forms called clitics (Booij, 1995, p. [65). Clitics can either pro- or encliticize, but in Dutch enclisis is preferred. Schwa-initial clitics induce resyllabification if they attach to a preceding word with a final consonant. The clitic usually wins an onset, e.g., 'jk denk het'/Ik.denk.het/ $\rightarrow /$ ak.den.kat/ (or even /kdeg.kav). If several function words occur in sequence, contraction (fusion) can occur, i.e., cliticization plus partial deletion, e.g., 'dat ik'/dat.Ik/ $\rightarrow / \mathrm{dak} /$. These are phonological rules of connected speech above the word level in Dutch that have the most impact in sentence phonology (for additional rules see Booij, 1995, chapter 7).

Application of these phonological rules led to the set of speech syllables. In general, the rules apply depending on speech rate, style, and stress conditions, etc. In the present empirical investigation the effects of these rules were 
maximized. To achieve this, the connected speech level phonological rules were applied whenever it was possible (worst case scenario), i.e., whenever a phonological string was a possible input for these rules.

The phonological rules of the sentence level were implemented and were added to the existing computer programs used for the generation of the lexeme syllables. Then the modified programs were applied to the TROUW corpus again.

From the resulting 17642 speech syllables types 1124 syllables were removed because they were ill-formed. ${ }^{\circ}$ These were 367 syllable types without any nucleus, 57 syllable types with more than one nucleus and 700 syllable types with nuclei that were too long (i.e., three vowel phonemes) yielding $6.37 \%$ of all 17642 syllable types generated. The cleaned list of speech syllables comprised 16518 types which had a mean token frequency of 91.09 (per one million word forms) $(S D=982.30$ ). In order to compare the 12027 lexeme syllables from TROUW with the 16518 speech syllables from TROUW, both lists were matched and the subset of syllable types represented in both lists was determined.

\section{Comparison of Lexeme and Speech Syllables}

Table 5 shows how often (per one million words) each higher level phonological rule was applied to the TROUW corpus. The high frequency of application of assimilation rules is striking. These rules applied whenever a voiceless obstruent was followed by a voiced fricative (progressive voice assimilation), a voiceless obstruent by a voiced stop (regressive voice assimilation), or a nasal

8. The reason why ill-formed syllables occurred at all was that the newspaper corpus contained all kinds of texis, e.g., crossword puzzles, chess puzzles, stock reports, sport reports, etc. III-formed syllables were likely to arise when character strings contained in these "lexts" were syllabified. Another source of illformedness were abbreviations, acronyms (some of which are high-frequent in Dutch, e.g., 'a.u.b. ' 'blz', 'hI', etc.). (foreign) proper names, loanwords, etc. Due to the fact that the trancription component had neither a morphological parser nor a lexicon in which word forms could be looked up in order to decide whether a particular word form was a proper word, a non-word, an abbreviation, or a proper name, the illformed syllables had to be filtered out at this point in the processing. by a non-coronal stop (nasal assimilation). Those contexts occurred with high frequency in the corpus. The high number of $/ \mathbf{n} /$-deletions is due to the fact that application of this rule on the word level was blocked in order to give resyllabification the possibility to apply. By far the most frequently applied rule is extemal sandhi resulting in resyllabification. In total, sentence. level phonological rules were applied 378.000 times per million words. Thus, on average, every third word was affected by application of a sentence-level rule. To our knowledge, the present study is the first one to provide an est $\mathrm{j}$. mate of the frequency of application of sentence-level rules.

Given the high rate of rule application, strong effects on the syllable inventory may be expected. We compared the size of the lexeme and speech inventories and the distribution of ditferent syllable types in each of them. There were many more syllable types in the speech than in the lexeme syllable inventory. 11050 syllable types appeared in both corpora, 977 only in the lexeme but not in the speech corpus, and 5468 only in the speech, but not in the lexeme corpus.

Figure 5 illustrates the distribution of the lexeme and speech syllables in terms of rank-frequency curves. In fact, both curves cross each other, i.e., the high-frequent lexeme syllables have a higher frequency than the high-frequen-

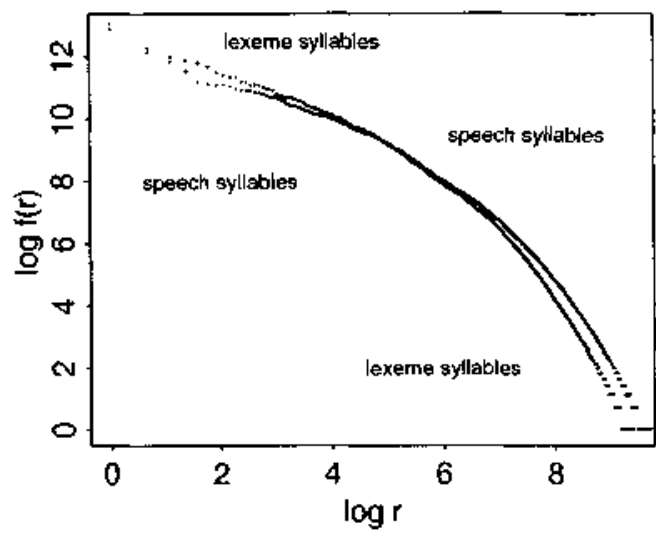

Fig. 5. Plot of the distribution of lexeme and speech syl)ables in terms of rank-frequency curves. 
Table 5. Relative Frequency of Application of Phonological Rules on the Sentence Level.

\begin{tabular}{|c|c|c|}
\hline phonological rule & $\begin{array}{l}\text { frequency of application } \\
\text { (per one million word forms) }\end{array}$ & segmental effect \\
\hline progressive voice assimilation & 37,188 & $|z, v, \mathrm{y}| \rightarrow|\mathrm{s}, \mathrm{f}, \mathrm{x}|$ \\
\hline regressive voice assimilation & 42,691 & $\begin{array}{l}\mid \mathrm{s}, \mathrm{f}, \mathrm{x} />/ \mathrm{z}, \mathrm{v}, \mathrm{v} / \\
\mathrm{p}, \mathrm{t}, \mathrm{k} />/ \mathrm{b}, \mathrm{d}, \mathrm{g} /\end{array}$ \\
\hline násal assimiłation & 11,683 & $/ \mathrm{n} />/ \mathrm{n}, \mathrm{n}, \mathrm{m} /$ \\
\hline $\begin{array}{l}\text { C-cluster simplification } \\
\text { (including degemination) }\end{array}$ & 4,428 & 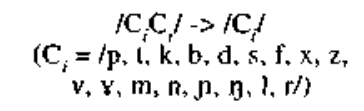 \\
\hline$/ n /$-deletion & 95.455 & $f n />\mid \phi l$ \\
\hline external sandhi & 160,864 & shift syllable boundary \\
\hline lusions (total) & 1.595 & fuse pronouns with auxiliaries \\
\hline cliticizations (1otal) & 21,293 & cliticize pronouns to hosts \\
\hline
\end{tabular}

sum

375,196

cy speech syllables, whereas with respect to the low-frequency syllables the speech syllables have a higher frequency than the low-frequency lexeme syllables. The speech syllable inventory was more diverse in terms of syllable types than the lexeme syllable inventory. Figure 5 shows that this higher diversity is for the most part a result of additional low-frequency syllable types (cf., the difference in the number of rank positions between both curves). The high number of new types among the speech syllables is mainly due to the fact that the sentence-level rules generated syllables that were not allowed on the word level. $2812(51.43 \%)$ of the "newcomers" ended in voiced obstruents. These syllables were created by application of regressive voice assimilation. Due to the application of final devoicing, the lexeme syllable inventory did not include any syllables with final voiced obstruents. $298(5.45 \%)$ of the newcomers included consonant clusters that were not permitted at the word level. As discussed above, we assumed, following Laeufer (1995) and Booij (1995), that collocational constraints are relaxed in fast speech and that the general sonority-based constraints determine syllabification. Therefore, syllables such as $/ \mathrm{kfru} /$ and $/ \mathrm{ksli} /$ were created.

Table $6 a$ gives an overview of the relative frequencies of the most common $\mathrm{CV}$ structures in the lexeme and speech syllable type inventories. The most frequent $\mathrm{CV}$ structures were the same in the three inventories, but their ranking differed. On the whole, the most frequent TROUW speech syllable types were more complex in terms of CV structure than the lexeme syllable types.

Next, the token frequencies of the syllables in the two inventories were compared. Overall, the correlation of syliable frequencies between the two inventories was high: $r_{s}=0.90^{* *}$ when calculated only across those syllables inciuded in both inventories (intersect), and $r_{s}=0.62^{* *}$ when all syllables were included and the frequency of the syllables that were only represented in one of the inventories was set to zero in the other inventory (join). Thus, generally speaking, the lexeme frequencies represented a reasonable estimate of the frequencies in the speech syllable inventory.

We specifically examined the token frequencies of those syllables directly affected by the application of the sentence-level phonological rules. Progressive voice assimilation devoiced syllable-initial fricatives. The effect of progressive voice assimilation is difficult to estimate, however, because the effect might interact with resyllabifications due to the Onset Principle: a fricative that became voiceless in syllable-ini- 
Table 6a. CV Structures and Corresponding Proportion of All Syllable Types.

\begin{tabular}{|c|c|c|c|c|c|}
\hline \multicolumn{2}{|c|}{$\begin{array}{c}\text { CELEX } \\
\text { lexeme syllables }\end{array}$} & \multicolumn{2}{|c|}{$\begin{array}{c}\text { TROUW } \\
\text { lexeme syllables }\end{array}$} & \multicolumn{2}{|c|}{$\begin{array}{c}\text { TROUW } \\
\text { speech syllables }\end{array}$} \\
\hline CV structure & $\begin{array}{c}\% \text { of all } \\
\text { syllable types }\end{array}$ & CV structure & $\begin{array}{c}\% \text { of all } \\
\text { syllable types }\end{array}$ & CV structure & $\begin{array}{c}\% \text { of all } \\
\text { syllable types }\end{array}$ \\
\hline CVVC & 16.37 & CVCc & 15.62 & CVCC & 13.33 \\
\hline CVC & 13.03 & CVVC & 12.17 & $\mathrm{CCVC}$ & 11.44 \\
\hline $\mathrm{CVCC}$ & 12.66 & CVC & 10.91 & ccvve & 11.29 \\
\hline CVVCC & 10.35 & $\mathrm{CCVC}$ & 10.28 & CVVC & 10.98 \\
\hline CCVVC & 9.52 & ccrve & 9.26 & CCvec & 8.91 \\
\hline CCVC & 9.08 & crvec & 8.69 & cVVce & 8.72 \\
\hline CCVCC & 6.07 & CCVCC & 7.24 & CVC & 8.48 \\
\hline cCVVCC & 4.42 & CVCC & 5.01 & CCVVCC & 5.74 \\
\hline CCVV & 3.96 & CCVVCC & 4,12 & CVCCC & 3.92 \\
\hline cVCCC & 3.27 & CCVV & 3.31 & CCVV & 3.28 \\
\hline CVV & 2.99 & CVV & 1.88 & CCVCCC & 1.99 \\
\hline CCVCCC & 1.15 & CCVCCC & 1.72 & CCCVC & 1.57 \\
\hline crvecc & 1.04 & VCC & 1.36 & $\mathrm{CVV}$ & 1.39 \\
\hline VC & 0.89 & CVVCCC & 1.22 & cccvve & 1.25 \\
\hline VVC & 0.88 & CCCVC & 1.06 & CVVCCC & 1.07 \\
\hline
\end{tabular}

tial position due to progressive voice assimilation may be in second position at the end of the derivation, that is, after all sentence-level rules have applied. In the set of lexeme syllables there were 3291 syllables $(27.36 \%)$ beginning with a voiceless fricative, i.e., [f], [s], or $[\mathrm{x}]$, whereas in the corpus of speech syllables there were $\mathbf{4 7 5 5}$ such syllables $(28.79 \%)$. Although the relative numbers hardly differ - possibly because of the reason mentioned above -, the absolute numbers partially reflect the effect of progressive voice assimilation. Regressive voice assimilation introduced syllables ending in yoiced obstruents. The occurrence of such syllables, which was $1346(=11.19 \%)$ in the lexeme corpus, was $4209(=25.48 \%)$ in the speech corpus. As regressive assimilation applied to syllables with voiceless final obstruents, the relative frequencies of those syllables was lower in the speech than in the lexeme corpus (7819 (47.34\%) vs. $6930(57.62 \%)$ ).

Fusion and cliticization eliminated all the full forms of clitics and pronouns, which had a frequency of 21,293 in the lexeme syllable inventory. $/ \mathbf{n}$-deletion reduced the frequency of syllables ending in /an/ from $6.45 \%$ to $2.64 \%$ of al] syllables. The proportion of syllabies ending in $/ 2 /$ increased from $12.34 \%$ to $18.41 \%$.
Because of the frequent application of external sandhi, we expected that the lexeme and speech syllable inventories would differ strongly in the distribution of syllables with different CV structures. In particular, the speech syllables should have more complex onsets than lexeme syllables. Table 7 shows that syllables without an onset appeared less frequently among the speech than the lexeme syllables. Thus, as expected, such syllables tended to gain an onset. By contrast, syllables with one or with more onset consonants appeared more frequently among the speech syllables than among the lexeme syllables.

Table 7 also shows the frequencies of syllables differing in coda complexity. One might expect speech syllables to have less complex codas, because coda consonants are often drawn into the onset of the following syllable. However, cliticization may increase the complexity of codas. As can be seen from Table 7 , the frequencies of syllables with different coda types were almost identical in the two corpora (complex codas in ca. $8 \%$ of the tokens in both inventories).

Thus, in spite of the massive application of the sentence-level rules, the effects on the distribution of syliables with different $\mathrm{CV}$ struc- 
Table 6b. CV Struciures and Corresponding Proportion of All Syllable Tokens.

\begin{tabular}{|c|c|c|c|c|c|}
\hline \multicolumn{2}{|c|}{$\begin{array}{c}\text { CELEX } \\
\text { lexeme syllables }\end{array}$} & \multicolumn{2}{|c|}{$\begin{array}{c}\text { TROUW } \\
\text { lexeme syllables }\end{array}$} & \multicolumn{2}{|c|}{$\begin{array}{c}\text { TROUW } \\
\text { speecb syilables }\end{array}$} \\
\hline CV structure & $\begin{array}{c}\% \text { of syllable } \\
\text { tokens }\end{array}$ & CV structure & $\begin{array}{c}\% \text { of syllable } \\
\text { tokens }\end{array}$ & CV structure & $\begin{array}{c}\% \text { of syllable } \\
\text { tokens }\end{array}$ \\
\hline cVv & 36.28 & CVV & 30.96 & cVV & 38.48 \\
\hline CVVC & 16.24 & CVC & 21.3 & $\mathrm{CVC}$ & 23.68 \\
\hline CVC & 16.20 & CVVC & 18.35 & CVVC & 14.75 \\
\hline VC & 9.49 & VC & 8.29 & CCVV & 5.06 \\
\hline VVC & 5.57 & CVCC & 3.58 & CVCC & 3.63 \\
\hline CVCC & 3.04 & CCVV & 3.54 & Ccve & 3.23 \\
\hline cCVv & 2.58 & VVC & 3.30 & VC & 2.68 \\
\hline cVvec & 2.47 & CVVCC & 2.29 & CVVCC & 1.94 \\
\hline ( CVC & 2.00 & ceve & 2.23 & cevve & 1.70 \\
\hline cevve & 1.57 & VV & 1.66 & VVC & 1.27 \\
\hline VV & 1.52 & cevve & 1.51 & VV & $|.0|$ \\
\hline $\mathrm{VCC}$ & .89 & VCC & .68 & $\mathrm{CCVCC}$ & .72 \\
\hline CCVCC & .58 & CCVCC & .58 & CCVVCC & .46 \\
\hline cCVvec & .39 & CCVvCC & .49 & CvecC & .34 \\
\hline crece & .30 & CVecC & .38 & CCCVV & .29 \\
\hline
\end{tabular}

tures were limited. Table $6 \mathrm{~b}$ shows the token frequencies of the most common syllables. In both inventories the three most common types of CV structure are, in order of frequency. CVV, $\mathrm{CVC}$. and $\mathrm{CVVC}$, logether accounting for more than $70 \%$ of all syllables. As mentioned, many new types of syllables were added to the inventory by application of sentence-level phonological rules. But because the token frequencies of most of these newcomers were very low, the relative frequencies of syllables with different $\mathrm{CV}$ structures were hardly changed.

The most salient difference between Tables 6a and $6 \mathrm{~b}$ is that the CVV syllable is by far the most frequent type of syllable with respect to token frequency in all three sets, whereas this syllable type is not among the ten most frequent types with respect to type frequency. Another finding is that $\mathrm{CV}$ types without onset (e.g., VC, VCC, VV, VVC. etc.) are dispreferred if we look at the type frequencies but, in fact, they are relatively frequent if we consider the tokens. This means that there are some $\mathrm{CV}$ structures in Dutch (e.g., CVV) that do not occur in many syllable types, but the ones that have this CV structure are high-frequent.

Table 7. Distribution of Types of Onsets and Codas among the Lexeme and the Speech Syllables fBoth lrom TROUW).

\begin{tabular}{|c|c|c|c|c|}
\hline \multirow[t]{2}{*}{ type of constituent } & \multicolumn{2}{|c|}{ lexeme syllables } & \multicolumn{2}{|c|}{ speech syllables } \\
\hline & $\begin{array}{l}\text { proportion } \\
\text { of tokens }\end{array}$ & $\begin{array}{l}\text { proportion } \\
\text { of types }\end{array}$ & $\begin{array}{l}\text { proportion } \\
\text { of tokens }\end{array}$ & $\begin{array}{l}\text { proportion } \\
\text { of types }\end{array}$ \\
\hline \multicolumn{5}{|l|}{ onset } \\
\hline none & $14.13 \%$ & $4.23 \%$ & $5.27 \%$ & $2.97 \%$ \\
\hline $\mathrm{C}$ & $76.95 \%$ & $56.04 \%$ & $82.90 \%$ & $48.57 \%$ \\
\hline$\geq \mathrm{CC}$ & $8.93 \%$ & $39.73 \%$ & $11.84 \%$ & $48.46 \%$ \\
\hline none & $36.41 \%$ & $5.92 \%$ & $44.88 \%$ & $5.94 \%$ \\
\hline C & $55.21 \%$ & $45.83 \%$ & $47.52 \%$ & $46.23 \%$ \\
\hline$\geq C C$ & $8.38 \%$ & $48.25 \%$ & $7.60 \%$ & $47.83 \%$ \\
\hline
\end{tabular}




\section{CONCLUSIONS}

The present study provides an estimate of the frequency of application of a number of Dutch sentence-level phonological rules. In our corpus, approximately one out of three words was affected by application of such a rule. The inventories of lexeme and speech syllables differed from each other: the frequency of certain types of syllables was reduced in the speech syllable inventory, while that of others was increased. The most important result is that the total number of syllable types was much larger in the speech than in the lexeme inventory because many types of syllables were not permitted on the word level, but occurred on the sentence level because phonotactic constraints were weakened. ${ }^{9}$ However, because the token frequency of most of these newcomers was low, the relative token frequencies of syllables with different $\mathrm{CV}$ structures were very similar in the two inventories.

An unexpected, but very interesting finding was that the $\mathbf{5 0 0}$ most frequent syltable types sufficed to generate almost $85 \%$ of all syllable tokens of the CELEX corpus. A similar calculation for English using the English lexical database of CELEX revealed a comparable finding. In English, the 500 most frequent syllables cover $80 \%$ of all the syllable tokens. As mentioned in the Introduction, Levelt and Wheeldon (1994) have sugggested that speakers may retrieve precompiled articulatory programs for high-frequency syllables from a mental syllabary. The finding of the present study that the large majority of the word tokens could be generated from a fairly small number of syllable types supports Levelt and Wheeldon's assumption that access to a syllabary would reduce the computational load during phonetic encoding. Thus, a mental syllabary may indeed be a device at the speaker's disposition.

9. In fact, this has also been acknowtedged by phonologists. Some constraints on syllable structure are turned off at a higher level of speech, and thus types of syllables can be created that are not allowed for by the lexical syllabification algorithm (Bopij. 1995; 126). According to Lieufer (1995), collocational constraints are reluxed in fast speech and the general sonoritybased constraints determine syllabification.
The practical consequences of this study are straightforward: inventories of lexeme syllables appear to provide a reasonable estimate of syllable frequencies in connected speech. Investigators, however, should remember that the frequencies of certain types of syllables - those affected by the application of sentence-level phonological rules - may be over- or underestimated, and that in connected speech many syllable types will occur that cannot occur at the word level. Syllables that begin with a vowel, for instance, are very likely to gain an onset. Experimenters should be careful with this kind of syltable. In general. speech syllables became more complex in terms of $\mathrm{CV}$ structure. Special attention should also be paid to syllable-final obstruent voicing and devoicing. There are a number of voice-assimilation rules in Dutch that apply on different levels in the course of the speech production process and often change the quality of final obstruents in terms of voicing. Finally, syllables used in experiments should not constitute potential clitics because cliticization is a common pheromenon in Dutch and often leads to segmental modifications of syllables or to resyllabifications.

Finally, we wish to draw the reauer s allchtion to the limitations of the present study. Obviously, a written text cannot be turned into spoken discourse simply by applying sentencelevel phonological rules. Although the basic syntactic rules are the same, spoken and written language differ in many ways, such as sentence length and complexity (Chafe, 1992: Hayes. 1988; Kroll, 1977; Redeker. 1984). It scems unlikely that these differences entail large differences in the occurrence of contexts permitting the application of sentence-level phonological rules, but this is, of course, an empirical issue. Spoken language may include elements. such as interjections. that rarely occur in writing; hence, the frequencies of these syllables were definitely underestimated in the present study. Most importantly, sentence-level phonological rules were applied whenever permitted by the segmental context. Almost certininly. speakers use sentence-level phonological rules more sparingly. Thus, in reality the differences between lexeme and speech inventories are likely to be smaller than those described here. 


\section{REFERENCES}

Bagemihl, B. (1995), Language games and related areas. In J.A. Goldsmith (Ed.). The handbook of phonological theory (pp. 697-712). Cambridge. Oxford: Blackwell.

Bell, A., \& Hooper. J.B. (1978). Issues and evidence in syllabic phonology. In A.J. Bell \& J.B. Hooper (Eds.), Syllables and segment (pp. 3-22). Ainsterdam, New York, Oxford: North-Holland.

Berendsen, E. (1986). The phonology of cliticization. Dordrecht. Riverion: Foris.

Berg. T. (1992). Umrisse einer psycholinguistischen Theorie der Silbe JOutline of a psycholinguistic theory of the syllable!. In P. Eisenberg. H. Vater, \& K.-H. Rimers (Eds.), Silbenphonologie des Deutschen (pp. 45-99) [Syllable phonology of German]. Tübingen: Narr (Studien zur Grammatik; 42).

Bertoncini, J., \& Mehler, J. (198I). Syllables as units in infan1." speech perception. Infant Behavior and Development. 4, 247-260.

Blevins, J. (1995). The syltable in phonological theory. In J.A. Goldsmith (Ed.). The handbook of phonolo. gicat theory (pp. 206-244). Cambridge. Oxford: Blackwell.

Bonij. G. (1995). The phonology of Dutch, Oxford: Clarendon Press.

Boojj, G., \& Rubach, J. (1987). Postcyclic versus postlexical rules in lexical phonology. Linguistic Inquiry, IX, 1.44 .

Bradley, D.C., Sánchez-Cásas, R.M., \& García-Albea, J. E. (1993). The status of the syllable in the percepion of Spanish and Engjish. Language and Cognitive Processes, 8, 197-233.

Browman. C.P., \& Goldstein, L. (1989). Articulatory gestures as phonological units. Phonology. 6, 20125 !

Burnage, G. (1990). CELEX. A gaide for users. Nijmegen: Centre for Lexical Information.

Chafe, W. (1992). Information flow in speaking and writing. In P. Downing, S.D. Lima, \& M. Noonan (Eds.), The lingtristics of literacy (pp. 17-29). Amsterdam: Benjamirs.

Chitashvili, R.J., \& Bayyen, R.H. (1993). Word frequency distributions. In L. Hřcbíček, \& G. Altmann (Eds.), Qinamitative text andalysis (pp. 54-135). Trier: Wissenschaftlicher Verlag (Quantiative Linguistics; 52).

Clements. G.N. (1990). The role of the sonority cycle in core syllabificition. In J. Kingston, \& M.E. Beckman (Eds.). Papers in laboratory phonology 1. Be'the'en the srammar and physics of speech (pp. 283 333). Cambridge: Cambridge University Press.

Cowan. N. Braine, M.D.S.. \& Leavitt, L.A. (1985), The phonological and metaphonological representation of speech: Evidence from fluent backward talkers, Jour. nal of Memory and Langurage, 24, 679-698.

Crompton, A. (1981). Syllables and segments in speech production. Linguistic:s, 19, 663-716.

Cutler, A. (1995), Spoken word recognition and production. In J.L. Miller \& P.D. Eimas (Eds.), Speech. langikathe. and commonication (pp. 97-136). San Diego: Academic Press.
Cutler, A.. Mehler, J., Norris, D.G., \& Segui, J. (1986). The syllable's differing role in the segmentation of French and English. Journal of Memory and Language, $25,385-400$.

Davis, S. (1982). Rhyme, or reason? A look at syllableinternal constituents. In M. Macaulay \& O.D. Gensler (Eds.), Proceedings of the Eighth Annual Meeting of the Berkeley Linguisticy Soriety. 13-15 February, 1982 (pp. 525-532). Berkeley: Berkeley Linguistic Society.

Dupoux. E. (1993). The time course of prelexical processing: The syllabic hypothesis revisited, In G.T.M. Altmann, \& R. Shillcock (Eds.), Cognitive modets of speech processing: The second Spertonga meeting (pp. 8I-1 14). Hove, Hillsdale: Lawrence Eribaum.

Fallows, D. (1981). Experimental evidence for English syllabification and syllable structure. Sournal of Linguistics, 17, 309-317.

Ferguson, C. (1976). Remarks on theories of phonological development. In W. von RafHer-Engel \& Y. Lebrun (Eds.), Baby talk and infaut speech (pp. 84-98). Amsterdam: Swets \& Zeitlinger.

Ferrand, L.. Segui. J., \& Grainger, J. (in press). Masked priming of word and picture naming: the role of sy!labic units. Journal of Memory and Langutige.

Fowler, C.A., Treiman, R., \& Gross. J. (1993). The structure of English syllables and polysyllables, Journd of Memory and Language, 32, 115-140.

Fujimura, O. (1975). Syllable as a unit of speech recog* nition. IEEE Transactions on Acoustic.s. Speech, and Signal Processing ASSP-2.3, 82-87.

Gerken, L.A. (1994), Young children's representations of prosodic phonology: Evidence from English-speakers" weak syllable productions. Journat of Memory and Language, 33, 19-38.

Good, I.J. (1953). The population frequencies of species and the estimation of population parameters. $B i$ ometrika, 40.237.264.

Greenberg, J.H., Osgood, C. E., \& Jenkins, J.J. (1963). Memorandum concerning language universals. In J.H. Greenberg (Ed.), Universals of language (pp. XV-XXVIi). (Second edition: 1973) Cambridge: MIT Press.

Hayes, D.P. (1988). Speaking and writing: distinct patterns of word choice. Journal of Menory and Language. 27, 572-585.

Hoard, J.E. (1971). Aspiration, tenseness, and syllabification in English. Language, 47. 133-140.

Hombert, J.-M. (1986). Word games: Some implicalions for analysis of tone and other phonological construc1s. In J.J. Ohala \& J.J. Jaeger (Eds.). Experimental phonology (pp. 175-186). Orlando: Academic Press.

Hulst, H. van der (1984). Syllable struchure and stress in Dutch. Dordrecht. Cinnaminson; Foris.

Hulst, H. van der, \& Lahiri, A. (ms). Remarks on phonetic and phonological representations for the CELEX database.

Itô, J. (1986). Syllabie theory in prosodic phomolosy. Amherst: University of Massachusetıs Ph.D. dissertation. Published by Garland Press, New York. 1988.

Itô. J. (1989). A prosodic theory ol epenthesis. Naturat Language and Linguistic Theory. 7. 217-259. 
Jusczyk, P.W. (1994). Infant speech perception and the development of the mental lexicon. In J.C. Goodman \& H.C. Nusbaum (Eds.), The development of speech perception: The transition from speech sounds to spoken words (pp. 227-270). Cambridge MA, London: MIT Press.

Jusczyk, P.W., Jusczyk, A.M., Kennedy, L.J., Schomberg, T., \& Koenig, N. (1995). Young infants' retention of information about bisyllabic utterances. Journal of Experimental Psychology: Human Perception and Performance, 2J, 822-836.

Kager, R. (1989). A metrical theory of stress and destressing in English and Dutch. Dordrecht, Providence RI: Foris.

Kager, R., \& Zonneveld, W. (1986). Schwa, syllables and extrametricality. The Linguistic Review, 5, 197. 222.

Kahn, D. (1976). Syllable-based generalizations in English phonology. New York, London: Garland.

Kensiowicz, M. (1994). Phonology in generative grammar. Cambridge MA, London: Blackwell.

Kiparsky, P. (1973). 'Elsewhere' in phonology. In S. Anderson \& P. Kiparsky (Eds.), A Festschrift for Morris Halle (pp. 93-106). New York: Holt, Rinehart and Winston.

Kiparsky, P. (1982). From cyclic to lexical phonology. In H. van der Hulst \& N. Smith. (Eds.), The structure of phonological representations (pp. 131-175) Part 1. Dordrecht: Foris.

Kiparsky, P. (1985). Some consequences of lexical phonology. Phonology Yearbook, 2, 83-138.

Krolt, B. (1977). Combining ideas in written and spoken English: a look at subordination and coordination. In E.O. Keenan \& T.L. Bennett (Eds.), Discourse across time and space (pp. 69-107). Los Angeles (Southern California Occasional Papers in Linguistics; 5).

Kuriłowicz. J, (1948), Contribution à la théorie de Ja syllable [Contribution to the theory of the syllable]. In \. Kuritowicz (Ed.) (1973). Esquisses linguistiques l (pp. 193-220). Deuxième édition, München: Fink. (Internationale Bibliothek für allgemeine Linguistik; I6, I).

Laeufer, C. (1995). Effects of tempo and stress on German syllable structure. Journal of Linguistics, 31, 227-266.

Lahiri, A., \& Coreman, J. (1988). Syllable weight and quantity in Dutch. In H. Borer (Ed.), Procedings of the $7 \mathrm{th}$ West Coast Conference of Formal Linguistics 1988 (pp. 217-228). Stanford CA: Center for the study of tanguage and information, Stanford University.

Laycock, D. (1972). Towards a typology of ludlings or play-languages. Linguistic Communications, 6 . $61-113$.

Lefkowitz, N. (1991). Talking backwards, lonking forwards. The French language game Verian. Tubingen: Narr (Language in Performance: 3 ).

Levelt, C. C. (1994). On the acquisition of place. Leiden: HIL (HIL dissertations; 8).

Levelt, W.J.M. (1989). Speaking. From intention to arriculation. Cambridge, London: MIT Press.
Levelt, W.J.M., \& Wheeldon, L. (1994). Do speakers have a mental syllabary? Cognition, 50, 239-269.

Liberman, I.Y., Shankweiler, D. Fischer, F. W., \& Carter, B. (1974). Explicil syllable and phoneme segmentation in the young child. Journal of Experimental Child Psychology, 18, 201-212.

Lindblom, B. (1963). Spectrographic study of vowel reduction. Journal of the Acoustical Society of America, 35, 1773-[781.

MacKay, D. (1970). Spoonerisms: The struciure of errors in the serial order of speech. Neuropswcholosit. 8, 323-350.

Macken, M. A. (1995). Phonological acquisition. In 3.A. Goldsmith (Ed.), The handbook of phonological thaory (pp. 67l-696). Cambridge, Oxford: Blackwell.

Maddieson, I. (1984). Patterns of stownd. Cambridge: Cambrigde University Press.

Mehler, J., Segui, J., \& Frauenfelder, U. (I981a). The role of the syliable in language acyuisition and perception. In T. Myers, J. Laver, \& J, Anderson (Eds.). The cognitive representation of specch (pp. 295-305). Amsterdam, New York, Oxford: Norh-Holland.

Mehler, J., Dommergues, J.Y.. Frauenfelder. U., \& Segui, J. (198 Jb). The sylubble's role in speech segmentation. Journal of Verbal Learning and Verfal Birhavior, 20, 298-305.

Mermelstein, P. (1975). Automatic segmentation ol speech into syllablic units. Journat of the Acoustion? Society of America, $58,880-883$.

Meyer, A.S. (1992). Investigation ol phonological encoding through speech error analyses: achieventents. limitations, and altematives. Cognition, 42, I81-211.

Mohanan, K.P. (1986). The theory of lexical phonotogy. Dordrecht: Reidel.

Nespor, M., \& Vogel, 1. (1982). Prosodic donains ol extemal sandhi rules. In H. van der Hulst \& N. Smilh (Eds.), The structure of phonological representafions (pp. 225-255), Part [. Dordrecht, Cinnaminsion: Foris.

Nooteboom, S. (1969). The tongue slips into patierms. In A.G. Sciarone, A.J, von Essen, \& A.A. de Ralak (Eds.), Nomen: Leyden studies in linguistics and phonetics (pp. 114-132). The Hague: Moutor.

Nusbaum, H., \& DeGroot, J. (1990). The role of syllatbles in speech perception. In M. Ziolkowski, M. Niske. \& K. Deaton (Eds.), Papers from the 26th Hegionat Meeting of the Chicago Lingaistic Socictr. Vafand 2: The parasession on the syllable in phometics of phonology (pp. 287-317). Chicago: Chicago Linguistic Society.

Pitt, M.A., \& Samuel. A.G, (1995). Lexical and sublexical feedback in auditory word recognition. Cinnirive Psychology, 29, 149-188.

Ramers, K.H. (1988). Vokalquantifiat and -qualitir im Deuschen [Vowel quantity and quality in Germim]. Tübingen: Niemeyer (Linguistische Arbezlen: 2 13 \}.

Redeker, G. (1984). On differences between spoken ind written language. Discourse Processes. 7, 4,7-,5.5.

Schiller, N.O., Meyer. A.S. \& Levelt. W.J.M. Isulhmi1ted). The syllabic structure of spoken words: evidence from the syltabification of intervocalic cortsonants. 
Schwartz, R.G., \& Goffman, L. (1995). Metrical pattems of words and production accuracy. Journal of Speech and Hearing Research, 38, 876-888.

Selkirk, E.O. (1982). The syllable. In H. van der Hulst, \& N. Smith (Eds.), The structure of phonological representations (pp. 337-393). Part II. Dordrecht: Foris.

Selkirk, E.O. (1984). On the major class features and syllabic theory. In M. Aronoff \& R.T. Oehrle (Eds.), Language sound structure. Studies in phonology presented to Morris Holle by his teacher and students (pp. 107-136), Cambridge, London: MIT-Press.

Shattuck-Hufnagel, S. (1979). Speech errors as evidence for a serial ordering mechanism in sentence production. In W.E. Cooper \& E.C.T. Walker (Eds.), Sentence processing (pp. 295-342). New York: Halsted Press.

Slis. I.H. (1984). Assimilation of voice in Dutch. In M.P.R. van den Broecke \& A. Cohen (Eds.), Proceedings of the Tenth International Congress of Phonetic Sriences (pp. 404-410). Dordrecht. Cinnaminson: Foris.

Stemberger, f.P. (1982). The nature of segments in the lexicon: Evidence from speech errors. Lingua, 56. 235-259.

Stroop. J. (19\%6). Some sandhi-phenomena in the southern Dutch dialects. In H. Andersen (Ed.), Sandhi phenomena in the langrages of Europe (pp. 145-155). Berlin. New York, Amsterdam: Mouton de Gruyter (Trends in Lingtaisties, Studies and Monographs; 33).

Treiman, R. (1983). The structure of spoken syllables: Evidence from novel word games. Cognition, 15,4974.

Treiman, R. (1986). The division between onsets and rimes in English syllables. Joumat of Memory and Language. 25, 476-491.

Treiman, R., \& Danis, C. (1988), Syllabification of intervocalic consonants. Journal of Memory and Language, 27, 87-104.

Treiman, R, \& Zukowski, A. (1990). Toward an understanding of English syllabification. Journal of Memory and Lunguage, 29, 66-85.

Trommelen, M. (1984). The syllable in Dutch. With special reference to diminutive formation. Dordrecht, Cinnaminson: Foris.

Vaissière, J. (1981). Speech recognition programs as models of speech perception. In T. Myers, J. Laver,
\& J. Anderson (Eds.), The cognitive representation of speech (pp. 443-457). Amsterdam. New York, Oxford: North-Holland.

Vennemann. T. (1982). Zur Silbenstruktur der deutschen Standardsprache [On the syllable structure of standard German]. In T. Vennemann (Ed.), Silben, Segmente, Akzente (Syllables, segments, accents) (pp. 261-305). Tübingen: Niemeyer (Linguistische Arbeiten; 126).

Vennemann, T. (1994), Universelle Nuklearphonologie mit epiphänomenaler Silbenstruktur [Universal nuclear phonology with epiphenomenal syllable structurel. In K.H. Ramers, H. Vater, \& H. Wode (Eds.), Universale phonologische Strukturen und Prozesse [Universal phonological structures and processes] (pp. 7-54). Tübingen: Niemeyer (Linguistische Arbeiten; 310 ).

Vogel, I. (1986). External sandhi rules operating between sentences. In H. Andersen (Ed.), Sandhi phe. nomena in the languages of Europe (pp. 55-64). Berlin. New York, Amsterdam: Mouton de Gruyter (Trends in Linguistics, Studies and Monographs: 33).

Vroomen, J. \& de Gelder, B. ( 1994). Speech segmentation in Dutch: no role for the syllable. In Procsed. ings of the 1994 International Conference on Spoken Langatage Processing, September 18 - 22, 1994, Yoko. hama. (pp. $1135-1138$ ).

Wheeldon, L.R. \& Levell, W.J.M. (1995), Monitoring the time course of phonotogical encoding. Jommat of Memory and Language, 34, 31 I-334.

White, C.M.N. (1955), "Backwards languages" in Africa. $\operatorname{Man}, 55,96$.

Wijnen, F., Krikhaar, E., \& Os, E. den (1994), The (non)realization of unstressed elements in children's utterances: Evidence for a rhythmic constraint. Journal of Child Language, 21, 59-83.

Zonneveld, W. (1983), Lexical and phonological properties of Dutch voicing assimilation. In $\mathbf{M}$. van den Broecke, V. van Heuven. \& W. Zonneveld (Eds.). Sound structures. Studies for Antonie Cohen (pp. 297312). Dordrecht, Cinnaminson: Foris.

Zwitserlood, P., Schriefers, H., Lahiri, A., \& van Donselaar, W. (1993), The role of syllables in the perception of spoken Dutch. Journal of Experimental Psychology: Learning, Memory, and Cognition. 19. $260-271$. 